\title{
LIMITES DEL CONOCIMIENTO METAFÍSICO, SEGÚN KANT Y TOMÁS DE AQUINO
}

\author{
Lorenzo Vicente-Burgoa \\ Universidad de Murcia \\ lvburgoa@um.es
}

\begin{abstract}
The comparative study between Kant and Thomas Aquinas regarding the limitations of metaphysical knowledge, yields notable coincidences, despite the clear differences between the systematic approach of each thinker. This makes it possible to appreciate in a better way the core of the question, and perhaps provides some help in the clarification of matters concerning the value of metaphysical knowledge. Despite appearances, our approach is not primarily historical, but systematic-philosophical. The cited authors will be used to the study a philosophical problem, and not as authority arguments. For that reason, we will confine ourselves to primary sources, without resorting to historical studies save for dispelling exegetical doubts or confirming the author's assertions.

Keywords: metaphysics, knowledge, Kant, Thomas Aquinas, limits of knowledge.
\end{abstract}

\section{Resumen}

El estudio comparativo de Kant y Tomás de Aquino, en cuanto al tema de las limitaciones del conocimiento metafísico presenta unas coincidencias notables, a pesar de las claras diferencias del enfoque sistemático de cada uno. Ello permite apreciar también mejor el nudo del problema y quizás clarificar un poco mejor las cuestiones relativas al valor del conocimiento metafísico. A pesar de las apariencias, nuestro enfoque no es primordialmente histórico, sino filosófico-temático. Los autores citados nos sirven para estudiar un problema filosófico y no tanto como argumentos de autoridad. Por ello nos atenemos a las fuentes primarias y no citamos estudios históricos, salvo para clarificar las dudas de interpretación o confirmar las aserciones del autor.

Palabras clave: metafísica, conocimiento, Kant, Tomás de Aquino, límites del conocimiento.

*Recibido: 17-04-09. Aprobado: 06-12-09. 


\section{Prólogo kantiano}

Después de la conocidas exigencias kantianas y su grave diagnóstico ${ }^{1}$ acerca de los males de la metafísica, ${ }^{2}$ es común entre los filósofos la conciencia de limitaciones en este tipo de conocimiento ${ }^{3}$.

Kant ha mirado a la metafísica desde el natural crecimiento o desarrollo científico. Y ha constatado que, al par que otros saberes van progresando e incluso algunos han llegado ya a su perfecto coronamiento - como sería el caso de la Lógica- o, al menos, han "tomado ya el seguro camino de la ciencia"; en cambio, en la Metafísica no se han dado

\footnotetext{
${ }^{1}$ El diagnóstico kantiano acerca del estado de la Metafísica en su tiempo, ha quedado plasmado en un acervo párrafo de los Prolegomena: "Que para la metafísica este tiempo [de destrucción] ha llegado, lo prueba el estado en que ella ha caído en todos los pueblos cultos, mientras que se cultivan celosamente, en cambio, las ciencias de toda especie. La antigua organización de los estudios universitarios conserva todavía su sombra[...]; pero ya no se la cuenta más entre las ciencias serias y uno puede juzgar por sí mismo cómo un hombre de espíritu, a quien se quisiese llamar gran metafísico, a duras penas aceptaría este elogio bienintencionado, no envidiado por nadie" (I. KANT: Prolegomena, ed. y trad. de M. Caimi, Madrid: Istmo 1999, solución, n. 366, p. 291; citaremos normalmente por esta edición). Frente a este oscuro panorama, Kant confía en un renacimiento de la Metafísica, en base a la crítica (Prolegomena, Solución, n. 367).

${ }^{2}$ Aunque hablemos de "Metafísica" habitualmente en este estudio, lo entenderemos de modo general, como "conocimiento metafísico", salvo que el contexto requiera la forma precisa de la ciencia que se denomina "Metafísica". Y entendemos por "conocimiento metafísico" el que cada pensador o cada sistema de pensamiento propone como el más fundamental o básico. En este sentido decimos que todo gran filósofo "tiene su metafísica".

${ }^{3} \mathrm{Al}$ hablar de "límite" debemos tener en cuenta también las observaciones de Kant: "el entendimiento que sólo se ocupa de su uso empírico, y que no reflexiona sobre las fuentes de su propio conocimiento, puede muy bien avanzar, pero hay algo que no puede hacer, a saber, fijarse a sí mismo los límites de su uso. Tampoco puede saber qué es lo que se halla dentro de su propia esfera y fuera de ella, ya que hacen falta para ello hondas investigaciones, como las que hemos iniciado" (KrV. A 238. Citaremos siempre, salvo indicación contraria, la traducción de Pedro Ribas. Madrid: Alfaguara 1978). Como comenta Marechal: "para conocer un límite como límite, es absolutamente necesario conocer objetivamente las dos regiones limítrofes, o bien, reconocer el límite por un solo lado en una tendencia a franquearlo, en la exigencia positiva o el apetito de un más allá. Apliquemos ahora esto al fenómeno." I. MARECHAL: El punto de partida de la Metafísica, tomo V, Madrid: Gredos 1959, p. 532.
} 
progresos y se halla estancada en su camino: la compara al tejido de Penélope, que va tejiéndose y destejiéndose al mismo tiempo; aparte de ser un campo de batalla constante entre sus seguidores y estar plena de palabrería vana y ociosa, etc. Sus males serían principalmente dos:

- No haber progresado, haberse estancado.

- No haber entrado todavía por el seguro camino del conocimiento científico.

Dada su importancia, es preciso hacer algo; y sobre todo, es preciso ver a qué se deben tales males y cuáles pueden ser los remedios.

Kant entiende que esos males se derivan, ante todo:

- Frente al idealismo, de que la metafísica ha dejado de lado la experiencia, la humilde y segura experiencia, por medio de la cual los objetos nos son dados. Esto se presenta, por una parte, como una necesidad para conocer algo a priori; mas por otra, como un desconocimiento o no reconocimiento de los propios límites, como una extralimitación indebida, ya que se pretende hacer un uso trascendente de sus conceptos y principios en relación con objetos reales. Se ignora que tal uso, al margen de la experiencia, solamente puede ser "trascendental", no trascendente, esto es, solamente en cuanto regulativo de las representaciones múltiples del sujeto cognoscente (fenómenos), no del comportamiento de las cosas en $\mathrm{si}^{4}$.

- Pero además, y frente al empirismo (de Hume) que no ha tenido suficientemente en cuenta la existencia del conocimiento a priori. Esto se presenta como la negación radical de la metafísica por parte del empirismo clásico de Hume. Mas también como desconocimiento de las limitaciones que impone el hecho de que las formas de universalidad y necesidad — que Kant mantiene como distintivas del conocimiento científico-, reclaman justamente tener en cuenta la legitimidad de las categorías y de los principios

${ }^{4}$ Cf. KrV. B 288, 294, 297, etc. 
metafísicos en cuanto al uso trascendente y realista de los mismos, en sus aplicaciones al mundo de la experiencia, que es para lo único que existe el conocimiento a priori ${ }^{5}$.

En cuanto a los remedios, parece claro que serán los antídotos contrarios: atenerse a la experiencia y contar con las formas puras del entendimiento, pero reconociendo a la vez los límites que esta estructura implica respecto del uso de la razón pura especulativa.

En concreto y para salvar la universalidad y necesidad del saber, se ha de recurrir a juicios o principios que, siendo universales, han de ser a priori y no pueden derivarse de la experiencia. Mas para conseguir el avance o progreso del conocimiento, habrá que recurrir a lo que constituye tal progreso, esto es, a juicios ampliativos; los cuales serán de carácter sintético, pues de lo contrario no serían propiamente ampliativos: lo que es analítico no es ampliativo, según Kant, ya que se encuentra ya dado en el sujeto del juicio, sin que añada ningún elemento nuevo o distinto. En consecuencia, se ha de acudir a juicios sintéticos ${ }^{6}$.

Esto, que es condición general de todo conocimiento especulativo, ha de ser tenido en cuenta igualmente en Metafísica, a fin de que ésta pueda entrar en el camino de la ciencia, o por lo menos, reconocer sus limitadas posibilidades y no transgredir "dialécticamente" (o sea, ilusoriamente) las fronteras de tales posibilidades.

Pero todo ello, claro está, implica una investigación mucho más amplia y profunda, si cabe, acerca del valor del conocimiento humano en general y especialmente del conocimiento que se llama científico. Esta investigación de Kant, como es sabido, ha sido justamente la crítica de la razón pura, la cual se presenta así como "prólogo obligado" de la Metafísica:

No entiendo por tal crítica la de libros o sistemas, sino la de la facultad de la razón en general, en relación con los conocimientos a los que puede aspirar prescindiendo de la

\footnotetext{
${ }^{5}$ Cf. KANT: Prolegómenos, prólogo, nn. 260-262.

${ }^{6}$ "La metafísica no se compone, al menos según su fin, más que de proposiciones sintéticas a priori" (KrV. B 18): Cf. Prolegom., \2, n. 266, etc.
} 
experiencia. Se trata, pues, de decidir la posibilidad o imposibilidad de una metafísica en general y de señalar tanto las fuentes como la extensión y límites de la misma, todo ello a partir de principios (KrV., pról. $1^{\text {a }}$ ed., A XII).

Dejando de lado ahora si ciertas afirmaciones son asumibles o no - como por ejemplo que lo universal no puede provenir de la experiencia y que solamente el juicio sintético es ampliativo del conocimiento: afirmaciones extremadamente discutibles e incluso inaceptables para muchos por fundarse en presupuestos inexactos ${ }^{7}$ — no parece desacertado que una de las raíces de los "males de la metafísica" se halla probablemente, o bien en la falta de conciencia de sus limitaciones (idealismo); o bien en una conciencia de tales limitaciones y restricciones, que de hecho la hacen imposible (como sucede en el empirismo) ${ }^{8}$.

$\mathrm{Y}$ en esto es justamente donde encontramos un punto de coincidencia muy sintomático con otros filósofos y metafísicos, en particular con los aristotélicos que desde siempre han reconocido más o menos explícitamente esas limitaciones del conocimiento metafísico; ello lo vemos especialmente en Tomás de Aquino. Y no solamente hay coincidencia con este diagnóstico kantiano referente a la conciencia de límites, sino

\footnotetext{
${ }^{7}$ Es Kant mismo quien confiesa esa ignorancia o imposibilidad: "Si la intuición tuviera que regirse por la naturaleza de los objetos, no veo cómo podría conocerse algo a priori sobre esa naturaleza. Si, en cambio, es el objeto (en cuanto objeto de los sentidos) el que se rige por la naturaleza de nuestra facultad de intuición, puedo representarme fácilmente esa posibilidad [...] me encuentro una vez más con el mismo embarazo sobre la manera de saber de él algo a priori; o bien supongo que los objetos, o lo que es lo mismo, la experiencia, única fuente de su conocimiento (en cuanto objetos dados), se rige por tales conceptos. En este segundo caso veo enseguida una explicación más fácil." KrV., pról. 2a ed., B XVII. Efectivamente, la clave para eso que Kant "no ve" (ni tampoco vio el empirismo de Hume) se ha perdido en la filosofía moderna, después de Guillermo de Ockham. Pero de hoc, alias.

8 "Nuestra razón no es una especie de llanura de extensión indefinida y de límites conocidos sólo de modo general, sino que más bien ha de ser comparada con una esfera cuyo radio puede encontrarse partiendo de la curvatura de su superficie (partiendo de la naturaleza de las proposiciones sintéticas a priori); desde ahí podemos igualmente señalar con seguridad el volumen y los límites de la esfera. Fuera de ésta (el campo de la experiencia) nada hay que sea objeto de la razón.” KrV., A 762.
} 
incluso en algunos puntos doctrinales básicos que conducen lógicamente a la justificación crítica de tales limitaciones.

Pero antes de pasar a estudiar la cuestión de los límites, parece conveniente poner de relieve el concepto mismo, que tiene Kant de la Metafísica o lo que él entiende por tal ciencia. Por tanto trataremos los siguientes puntos: (1) el concepto kantiano de Metafísica, (2) posturas básicas ante la Metafísica de límites y (3) los límites del conocimiento metafísico en Kant y en Tomás de Aquino.

\section{La idea de Metafísica, según Kant}

Es imprescindible, ante todo, señalar cuál era la idea que Kant tenía acerca de la Metafísica. Y dado por supuesto que, como se ha señalado ya, pueden encontrarse en Kant diversos conceptos de Metafísica, ahora nos interesa señalar especialmente los dos siguientes: como aspiración irrenunciable de la razón humana y como ciencia ${ }^{9}$.

Pero antes, veamos un texto menos conocido de Kant, en el que arriesga una definición de Metafísica a partir de su finalidad. Dice así: ${ }^{10}$

La Real Academia de Ciencias pide sean enumerados los progresos de una parte de la filosofía en una parte de Europa culta y aun para una parte del siglo en curso.

\footnotetext{
${ }^{9}$ En algún momento Kant describe a la Metafísica, incluso como "el inventario de todos los conocimientos que poseemos, sistemáticamente ordenados por la razón pura" $(K r V$., A XX). Es claro que no debe entenderse como un "inventario enciclopédico"; nada más lejos de Kant que tal idea, sino como un "sistema" rigurosamente organizado y organizador de todos los conocimientos humanos. En lo cual parece concordar también con el sentido aristotélico de "saber arquitectónico." Cf. ARISTÓTELES: Metaphys. I, 1, 981a25-30; y Tomás De AQuino: In Metaphys., Proemium; Ib. Lib. I, lec. 1, n. 24 ss. En análogo sentido alude Kant a una "arquitectónica de la razón pura" (Cf. $\mathrm{KrV}$., A $832 /$ B 860 y ss).

${ }^{10}$ Se trata de un concurso público convocado por la Academia Real de las Ciencias de Berlín en 1791 sobre el tema: ¿Cuáles son los efectivos progresos que la Metafísica ha hecho en Alemania desde los tiempos de Leibniz y Wolf? Kant concurre a esta convocatoria. Resultaron ganadores, a juicio del tribunal de la Academia de Berlín, los Sres. Schwab, Reinhold y Abicht.
} 
Esta parece tarea fácil de resolver, dado que no afecta sino a la historia; e igual que los progresos de la astronomía y de la química, en cuanto ciencias empíricas, han encontrado quienes escriban su historia, mientras que los del análisis matemático o de la mecánica pura, realizados en el mismo país y en la misma época, los encontrarán pronto y si se quiere, tampoco parece haber mayor dificultad en la ciencia aquí considerada.

Sólo que esta ciencia es la metafísica y ello hace que la cosa cambie por entero. Se trata de un mar sin riberas en donde el progreso no deja huella alguna, y cuyo horizonte carece de término visible que permitiera percibir cuán cerca se esté de él. Por lo que respecta a esta ciencia, que por lo demás ha quedado casi siempre tan sólo en idea, es muy difícil la tarea propuesta, tanto como para desesperar casi la posibilidad de resolverla; y aun si ello se lograra, la condición prescrita: poner ante los ojos en una breve disertación los progresos habidos, acrecienta encima la dificultad. Pues metafísica es, en su esencia e intención final, un todo acabado: o todo o nada. Lo que para su fin final se requiere no puede ser tratado pues fragmentariamente, como sería el caso en la matemática o la ciencia natural empírica, siempre en progreso sin fin. A pesar de ello, vamos a intentarlo.

La primera pregunta, y la más urgente, bien puede ser ésta: ¿qué es lo que propiamente quiere la razón con la metafísica? ¿Qué fin final tiene a la vista con su elaboración? Pues [él es] gran fin final, quizás el mayor y hasta el único fin final que la razón pueda proponerse en su especulación, dado que todos los hombres, en mayor o menor medida, participan en él; y no se concibe por qué, a pesar de lo infructuoso de sus esfuerzos en este campo, sería vano gritarles que cesen de una vez de darle vueltas a esta piedra de Sísifo, [260] si no fuese porque el interés que en ello tiene la razón es el más profundo que puede haber. 
Este final al que apunta [como disposición natural] la entera metafísica es fácil de descubrir, y es en este respecto donde puede fundamentarse una definición de la misma: ella es la ciencia encaminada al progreso del conocimiento de lo sensible a lo suprasensible por medio de la razón ${ }^{11}$.

Esto último nos muestra ya los dos aspectos que Kant intuye en el conocimiento metafísico, como aspiración al conocimiento de lo suprasensible y como saber dirigido por la razón.

\section{a) La Metafísica, como aspiración del espíritu humano.}

Ante todo, para Kant la Metafísica es una honda e irrenunciable aspiración del espíritu humano:

La Metafísica nos es dada, quizás más que cualquiera otra ciencia, por la naturaleza misma, según sus caracteres fundamentales, y no puede en modo alguno ser considerada como producto de una elección arbitraria o como ampliación casual de la experiencia (de la cual se separa de modo completo) ${ }^{12}$.

De aquí que el hombre no puede nunca renunciar a hacer metafísica, que es para él como el respirar un aire puro:

Es de esperar tan poco que el espíritu humano renuncie completamente, de una vez, a las investigaciones metafísicas, como que para no respirar un aire impuro, lleguemos a interrumpir completamente la respiración. Existirá siempre en el mundo, y lo que es más en todo hombre, especialmente en los hombres reflexivos, una metafísica, la cual, a falta de un patrón fijo, la cortará cada cual a su modo ${ }^{13}$.

${ }^{11}$ I. KANT: Los progresos de la Metafísica desde Leibniz y Wolf, estudio preliminar y traducción de Felix Duque, Madrid: Tecnos 1987, Primer manuscrito, Prólogo.

${ }^{12}$ Prolegomena, soluc. \57, n. 353.

${ }^{13}$ Prolegomena, soluc., n. 367 (Ed. Caimi, p. 291). 
O como dice en otros lugares: "De ahí que la razón humana, desde que pensó, o mejor dicho, meditó, nunca pudiera prescindir de la metafísica" (KrV., B 870). El mismo Kant, como pensador, es un ejemplo de esta irresistible aspiración del espíritu hacia un conocimiento metafísico. La Metafísica, pues, existirá siempre: "La metafísica ha existido siempre y existirá allí donde esté el hombre”; “... esta que es la más antigua de todas las ciencias, y que seguirá existiendo, aunque éstas desaparecieran totalmente en el abismo de la barbarie”; 15 “... se volverá siempre a ella, como a una amada con la que se ha tenido una desavenencia" 16 .

Es la Metafísica el coronamiento de todo conocimiento humano: "Por ello mismo es también la metafísica lo que corona todo el desarrollo de la razón humana" y aunque "como mera especulación sirva para evitar errores, mas que para extender el conocimiento, no disminuye su valor, sino que, al contrario, le da dignidad y prestigio en virtud de la censura que ejerce" 17 .

Estas ultimas frases nos muestran ya el sentido que la Metafísica tiene para Kant, como resultado de su análisis crítico. Pero ello depende también de lo que Kant entendió por Metafísica. Por lo demás, tomada la Metafísica como simple "disposición natural de la razón" sería realista:

... pero por sí sola... dialéctica y engañosa. Por consiguiente, si se pretende tomar de ella los principios y si se sigue, en su uso, la apariencia ilusoria, natural, ciertamente, pero no por ello menos falsa, no se puede tener nunca una ciencia, sino sólo un arte dialéctico vano ${ }^{18}$.

Veremos luego que esta concepción de la Metafísica como aspiración del espíritu y como coronamiento de todo el saber humano, respondería a lo que los aristotélicos califican como el "objeto extensivo" del intelecto humano, que no reconoce limitaciones. Para Kant será, sin duda, una de las raíces de la ilusión trascendental y del engaño dialéctico.

\footnotetext{
${ }^{14} \mathrm{KrV}$., Einleitung, VI; B 21.

${ }^{15} \mathrm{KrV}$., Pról. XIV.

${ }^{16} \mathrm{KrV}$., A 850.

${ }^{17} \mathrm{KrV}$., A 851.

${ }^{18}$ Prolegomena, solución n. 365 (Ed. Caimi, p. 287).
} 


\section{b) La Metafísica como ciencia}

El concepto kantiano de la Metafísica esta ligado estrechamente a la concepción racionalista e incluso típicamente wolfiana. En efecto, la Metafísica para Kant, como para los racionalistas, es una ciencia, que procede de principios a priori, con total independencia de la experiencia; y que debe seguir un método también puramente deductivo. Kant concuerda enteramente con esta concepción racionalista de la Metafísica:

La metafísica, conocimiento especulativo de la razón, completamente aislado, que se levanta enteramente por encima de lo que enseña la experiencia, con meros conceptos (KrV., pról. 2 ed., XIV).

Los principios que utiliza [la metafísica] no reconocen contrastación empírica alguna, por sobrepasar los limites de toda experiencia. El campo de batalla de estas inacabables disputas se llama metafísica ( $K r V$., pról. A VIII).

Esto lo había indicado ya en la Dissertatio de 1770: "La filosofía primera, que contiene los principios del uso del entendimiento puro es la Metafísica"19. La Metafísica debe partir de principios puramente inteligibles, sin contacto alguno con la experiencia ${ }^{20}$. Es una ciencia enteramente a priori:

Por lo que se refiere a las fuentes de un conocimiento metafísico, está ya implícito en su concepto que no pueden ser empíricas [...] Los principios de estas [...] jamás deben ser tomados de la experiencia, pues deben ser conocimientos, no físicos, sino metafísicos; esto es, más allá de la experiencia $[. .$.$] Es, pues, un comienzo a priori, o del entendimiento$ puro, o de la razón pura ${ }^{21}$.

19 "Philosophia autem prima continens principia usus intellectus puri est Metaphysica." De mundi sensibilis atque intelligibilis forma et principiis, \. 8.

${ }^{20}$ “Cum itaque in Metaphysica non reperiantur principia empirica, conceptus in ipsa obvii non quaerendi sunt in sensibus, sed in ipsa natura intellectus puri" De mundi sensibilis..., \. 8.

${ }^{21}$ Prolegomena, $\ 1$, n. 265. 
Y repite: "El conocimiento metafísico debe contener solamente juicios a priori, como exige la naturaleza de sus fuentes" (Ib., n. 2; ed. c., p. 52) En consecuencia, las fuentes, los puntos de partida y el método de la metafísica han de ser puros a priori, enteramente desconectados de la experiencia sensible. Y esta desconexión, no es sólo por el hecho de que sobrepasan la experiencia, sino justamente porque las fuentes de los mismos no provienen de la experiencia (por abstracción), sino que se hallan exclusivamente en la razón o en el entendimiento puro. Los textos kantianos son innumerables.

Es evidente que Kant concibe la Metafísica encerrada en el ámbito del entendimiento puro; enteramente desligada de la experiencia. Es más, el método propio de la Metafísica ha de cuidar rigurosamente de que el conocimiento sensitivo no traspase sus límites y se mezcle con los principios del entendimiento:

Todo el método de la metafísica sobre lo sensitivo y sobre lo intelectual, retorna siempre a este precepto principal: se ha de procurar con todo cuidado que los principios propios del conocimiento sensible no traspasen sus términos y contaminen los intelectuales ${ }^{22}$.

En consecuencia el concepto kantiano de la Metafísica coincide plenamente con la idea de la Metafísica racionalista, construida enteramente a priori, al estilo de la metafísica wolfiana:

Tenemos que seguir el que fue riguroso método del célebre Wolff, el más grande de los filósofos dogmáticos [...] Wolff estaba, por ello mismo, especialmente preparado para situar la metafísica en ese estado de ciencia ${ }^{23}$.

22 "Omnis metaphysicae circa sensitiva atque intellectualia methodus ad hoc potissimum praeceptum redit: sollicite cavendum esse, ne principia sensitivae cognitionis domestica terminos suos migrent ac intellectualia afficiant" De mundi sensibilis..., \& . 24.

${ }^{23} \mathrm{KrV}$., pról., 2a ed., B XXXVI. Si ahora recordamos cuál era el método wolfiano para la metafísica, tenemos: "Las reglas del método filosófico son las mismas que las del método de la matemática.” C. WoLfF: Logica, c. 2, n. 139. 
Esta es, pues, la única Metafísica o el único estilo de hacer metafísica, que Kant conoce; y que él denomina "metafísica dogmática", asumiendo indebidamente que ello equivalía a toda la metafísica precedente. Es, pues, muy diferente de la metafísica de inspiración realista-aristotélica y más cercana de la "Dialéctica" platónica. En efecto, la Metafísica de Aristóteles se caracteriza por basarse en la experiencia real del ser, como tal; elevándose luego, por medio de la abstracción de la forma eidética o esencial, la ratio entis ut sic (no por universalización arbitraria) al plano de lo trascendental; el método es típicamente analítico (via resolutionis) y real, pues procede desde lo complejo y posterior por naturaleza (secundum naturam) a lo simple y anterior, los principios y las causas primeras $^{24}$.

En cambio, la metafísica racionalista y la que Kant tiene en cuenta es una metafísica de lo a priori, de lo puramente ideal, sin contacto con y totalmente independiente de la experiencia; el método es sintético, a base de añadir sintéticamente a las formas puras los datos de la experiencia.

Una metafísica que tuviera su fundamento, siquiera remoto, en la experiencia, en la intuición empírica y la ulterior comprensión eidética del ser real, del existente real, es para Kant inconcebible. Kant no parece haber criticado este tipo de metafísica: sencillamente la desconoce ${ }^{25}$. Y no puede ni pensar en ella, ya que una tal metafísica solamente es con-

\footnotetext{
${ }^{24}$ Cf. TOMÁs DE AQuino: In Metaphys., II, lec. 1, nn. 278ss.

${ }^{25}$ Hay, sin embargo, un momento en el que parece que Kant ha entrevisto este tipo de metafísica que pudiera partir de la experiencia, tal y como parecía presentarse en el empirismo de Locke; lo que Kant, sin duda con razón, rechaza y descalifica: "Más recientemente pareció, por un momento, que una cierta fisiología del entendimiento humano (la del conocido Locke) iba a terminar con todas esas disputas y que se iba a resolver definitivamente la legitimidad de aquellas pretensiones. Ahora bien, aunque el origen de la supuesta reina se encontró en la plebeya experiencia común y se debió, por ello mismo, sospechar con fundamento de su arrogancia, el hecho de habérsele atribuido falsamente tal genealogía hizo que ella siguiera sosteniendo sus pretensiones. Por eso ha recaído todo, una vez más, en el anticuado y carcomido dogmatismo y, a consecuencia de ello, en el desprestigio del que se pretendía haber rescatado la ciencia” ( $\mathrm{KrV}$., pról. 1a ed., A IX-X). Nótese el despectivo calificativo de "fisiología del entendimiento" con el califica el intento empirista de Locke. Y luego, refiriéndose a la "supuesta reina" (sin duda, la Metafísica, considerada como "reina de las ciencias"), dice que se le atribuye "falsamente" una genealogía empírica vulgar, esto es, plebeya.
} 
cebible admitiendo la capacidad abstractiva de la mente y conociendo los diversos modos de la misma; cosa que Kant ha dejado de lado, al menos desde la Dissertatio: "El concepto intelectual abstrae de todo lo sensitivo, mas no es abstraído de lo sensitivo, por lo que quizás debería llamarse más propiamente abstrahente que abstracto" 26 .

El sentido es claro: se dan conceptos "abstrahentes", pero no "abstraídos"; es decir, existen en el entendimiento conceptos, que abstraen de suyo y por sí mismos de lo sensible; pero no son obtenidos por medio de una actividad abstractiva (no son abstracti, "abstraídos"), sino que están en él como conceptos puros a priori. Es la tesis clásica del conceptualismo medieval (G. de Ockham), seguida luego por la corriente racionalista cartesiano-wolfiana. En efecto, si admitimos la existencia de los "conceptos universales", como hace Kant, pero negamos que sean obtenidos por medio de una operación abstractiva, debemos decir que no son propiamente "abstraídos" (en pasiva: abstracti), sino "abstrayentes" por sí mismos ("abstrahentes", en voz activa) $)^{27}$.

${ }^{26}$ "Conceptus intellectualis abstrahit ab omni sensitivo, non abstrahitur a sensitivis, et forsitan rectius diceretur abstrahens quam abstractus" (De mundi sensibilis..., \6). Sobre el concepto kantiano de abstracción y para una mayor información remitimos a nuestro estudio: "¿Intuición pura o abstracción formal? (de Kant a Tomás de Aquino)", Pensamiento, 58 (2002), pp. 55-89. Aquí proponemos que las famosas "formas puras a priori" de Kant son aceptables si se las entiende como "abstractos formales puros". El mismo Kant parece haber seguido, sin saberlo, el proceso de abstracción formal para justificar la existencia de tal a priori puro. En efecto, para justificar el a priori puro, dice: "Lasset von euren Erfahrungsbegriffe eines Körpers alles, was daran empirisch ist, nach und nach weg"( $\mathrm{KrV}$., B5. Einleitung, II). Eso de "eliminar todo lo empírico" de nuestros conceptos, ¿qué otra cosa es sino "abstraer" la forma eidética, dejando de lado los datos empíricos?

${ }^{27}$ Esta aclaración es fundamental para ver la diferencia radical en la concepción aristotélica del conocimiento científico (universal y necesario), obtenido mediante una operación abstractiva de la mente, y la concepción racionalista, incluida la kantiana, de un conocimiento científico (que se considera también "universal y necesario"), pero cuyo origen sólo puede señalarse como puro a priori. La raíz de todo esto es antropológica: la concepción dualista del hombre, como dos mundos separados y meramente yuxtapuestos del racionalismo (con raíces lejanas en el platonismo), hace imposible el paso desde la sensibilidad a la racionalidad; la operación abstractiva carece ahora de sentido. Al fin, y por eso mismo, "las mónadas" intelectuales "no tienen puertas ni ventanas" (Leibniz) al mundo exterior. 
En consecuencia, la metafísica que Kant tiene ante los ojos es únicamente la Metafísica del racionalismo cartesiano, especialmente de Leibniz y Wolff. A ésta es a la que dirige su crítica ${ }^{28}$. Y a la que, en definitiva, declara imposible, en cuanto ciencia acerca del mundo real.

\section{Tres posturas básicas respecto a los límites de la Metafísica}

En efecto, la historia de este problema no comienza con Kant, como tendremos ocasión de ir viendo en este trabajo. Pudiéramos decir

\footnotetext{
${ }^{28}$ Como ya señaló acertadamente I. Marechal: "De ir al fondo de las cosas, el kantismo no alcanza la Escolástica aristotélica, menos aún el sistema tomista: la ignora. Kant se engaña cuando imagina haber hecho la crítica de toda la metafísica pasada, presente y futura, al hacer la de la metafísica racionalista; pero contra ésta, la única que realmente consideró, su razonamiento era válido. Corrijamos su error, y entonces sus conclusiones negativas se reducen a la inanidad, en el orden especulativo, de todo 'dogmatismo' metafísico, ni más ni menos; es decir, de toda doctrina que pretenda afirmar objetos que no serían ni dado en una intuición ni demostrables por una 'deducción trascendental' como condiciones lógicas de la posibilidad de objetos dados en una intuición. Los escolásticos practicaban, e incluso profesaban, desde siglos, esta exclusiva solemnemente proclamada por el filósofo crítico. Dicha exclusiva quiere decir, para ellos, que si el objeto metafísico no nos es dado, sea explícitamente en una intuición intelectual, sea implícitamente como condición universal de los objetos de nuestra experiencia, no podríamos afirmar su realidad más que mediante juicios indebidamente extensivos, en los cuales el predicado sería, por relación al sujeto lógico, un puro añadido instintivo o arbitrario: ahora bien, esta categoría de juicios 'sintéticos a priori' pareció siempre y con derecho, a los lógicos escolásticos, no menos que al filósofo de Königsberg, totalmente desprovista de verdadera evidencia racional, es decir, de necesidad objetivo-teórica — cualquiera que pudiera ser, por otra parte, su valor práctico. La Crítica kantiana fue destructiva, no por razón del principio metodológico que acabamos de recordar, sino porque deja de tomar en consideración una hipótesis que no es en modo alguno quimérica: aquella en que todo objeto, en la conciencia, estaría intrínsecamente constituido, en tanto que objeto, por una síntesis de acto y de forma, de tal manera que la reflexión crítica pudiera discernir, no solamente las propiedades lógicas de los escalonamientos formales, sino las propiedades lógicas de exigencias dinámicas — propiedades garantizadas, unas y otras por la necesidad primordial del pensamiento objetivo como tal". I. MARECHAL: El punto de partida de la Metafísica. V: El tomismo ante la filosofía crítica, Madrid: Gredos 1959, pp. 572-73.
} 
que con respecto a las limitaciones de la Metafísica hay tres posturas fundamentales:

(a) Una sería la de aceptación sin condiciones ni limitaciones: es la postura del ontologismo y del idealismo. Modernamente proviene de la idea de Guillermo de Ockham, según la cual, nuestra intuición, imitación de la divina, sirve para todo y llega a todo: incluso a lo meramente posible y a lo no existente ${ }^{29}$. De aquí que el conocimiento abstractivo, si no se niega, se deja de lado como innecesario, sino ya como inadecuado o incluso inútil; la intuición sirve para todo.

Por tanto, si nuestra intuición es como una imitación de la divina, podemos llegar a todo y el objeto de nuestro entendimiento es todo el ser, incluso el ser puramente posible. Tal será también el objeto de la metafísica: el ser comunísimo. Dios mismo, como dentro de ese objeto omniabarcante, será también de alguna manera objeto de intuición y la teología filosófica será un saber esencial acerca de Dios. Maxime si los conceptos se predican de modo unívoco, como pretende Escoto.

Esta doctrina, desde Escoto y a partir del nominalismo, se prolonga en los autores del s. XIV a XVI. El escolástico más significativo en la edad moderna sería Francisco Suárez, para quien el objeto de la metafísica es el ens quod abstrahit a finito et infinito, a possibili et necessario, ${ }^{30}$ etc. Por tanto, no hay limitación alguna para el conocimiento metafísico. Es muy probable que de él lo hayan tomado, más o menos inconscientemente, Descartes y los poscartesianos, especialmente Leibniz y Wolff. Este último dice: Metaphysica es scientia possibilium quatenus esse possunt ${ }^{31}$.

Es pues una metafísica, que no reconoce limitación alguna para el intelecto humano y se lanza a dogmatizar incluso sobre objetos completamente alejados de nuestra comprensión y de nuestra experiencia, como criticará certeramente Kant. Su raíz, suponer que nuestra intui-

29 "Notitia intuitiva rei est talis notitia virtute cuius potest sciri utrum res sit vel non". G. de OCKham: In I Sent., Prologus, q. 1. Cf. nuestro estudio: "Abstracción e intuición en Guillermo de Ockham o la encrucijada entre el pensamiento medieval y la filosofía moderna", en Estudios Filosóficos, 51 (2002), pp. 223-256.

${ }^{30}$ Cf. F. SuArez: Disp. Metaph., dist. 1, sec. 1, n. 26; dis. 2, sec. 2, nn. 15-20.

${ }^{31}$ Cf. WolfF: Logica, Pról. c. 29. 
ción es casi divina, omnicomprensiva, y que primum ontologicum est primum logicum (ontologismo). De aquí los argumentos ontológicos a priori para demostrar la existencia de Dios; cuyo valor niegan tanto Kant como Tomás de Aquino ${ }^{32}$.

(b) Está, por el extremo opuesto, la metafísica o pseudometafísica del empirismo clásico, para el que solamente conocemos impresiones sensibles y no podemos ir más allá de ninguna manera. De aquí que el empirismo, al reducir las ideas a impresiones debilitadas (Hume), ${ }^{33}$ les niega todo carácter universal, y sólo entiende lo general como lo colectivo o la suma indeterminada de particulares. No tiene en cuenta que, por ejemplo, el universal "árbol" no es un colectivo de árboles, no es lo mismo que un bosque. Se ignora que en la intuición concreta de lo particular, se halla también implícito lo universal, los caracteres universales, específicos o genéricos. Así, por ejemplo, en este árbol de mi jardín (individuo), que es un pino (especie), y un vegetal (orden remoto) y un viviente (género remoto), etc., se hallan también esos caracteres o determinaciones específicas y genéricas, que sirven justamente para la clasificación de tales entes naturales. Es lo que nombramos como el carácter de árbol (en abstracto: arboreidad), como de lo blanco decimos blancura y de hombre humanidad, etc.

El empirismo, al desconocer la vía de la abstracción formal, se queda sin la clave obligada para poder rescatar lo universal y lo constante en lo concreto individual y contingente, a través de su carácter o tipo o forma distintiva. Mas justamente por ello, carece de la base para una justificación crítica del saber científico: es el conocido "problema de Hume" respecto de la ciencia natural ${ }^{34}$.

(c) Están, finalmente, los que admiten un conocimiento metafísico, pero con condiciones y limitaciones, propias del instrumento de tal co-

\footnotetext{
${ }^{32}$ Cf. Tomás de Aquino: Sum. Theol. I, q. 2, a. 1c, ad 2m; C. Gent. I, cc. 10, 11; KANT: $K r V$., A 502-602.

${ }^{33}$ Cf. D. Hume: Tratado de la naturaleza humana, I, sec. 1. Cf. nuestro estudio: "La crítica de Hume al pensamiento abstracto," Pensamiento 53 (1997), pp. 425-451.

${ }^{34}$ Sobre ello, cf. nuestro estudio: "La abstracción formal y la validación del razonamiento inductivo" Sapientia, 62 (2007), pp. 129-178.
} 
nocimiento, que es el intelecto humano. En él no hay intuición directa, ni de los singulares materiales, ni de lo espiritual.

Todo su conocer depende de los datos sensibles, de los que debe extraer la forma universal de las cosas. Sólo que este intelecto es también razón, la cual puede saltar por semejanzas y analogías o por conexiones necesarias, desde un dato a otro; de modo que puede llegar incluso a la percepción del ser en su totalidad, de lo posible, etc. y de lo infinito, aunque negativamente. Es la evolución propia de una potencia que radica en una mente, que es forma del cuerpo (forma corporis physici organici, según la definición aristotélica del alma $)^{35}$ y no en un ente puramente espiritual, como supone el dualismo platónico y racionalista.

Entre los autores de esta posición pueden señalarse varios filósofos. Kant, sin duda, uno de ellos. Su negación de intuición intelectual se refiere claramente a la "intuición empírica" de objetos, sean inmateriales, sean materiales: no tenemos intuición ni experiencia acerca de lo espiritual; pero tampoco intuición intelectual de lo singular material, ya que no puede afectar a nuestra facultad de pensar. Y se trata de negar la "intuición intelectual empírica" propiamente dicha; ya que el mismo Kant admite en el intelecto la "intuición pura" de las categorías a priori, lo mismo que en la sensibilidad la intuición pura de sus categorías de espacio y tiempo.

Nótese la coincidencia con la tesis tomista, frente al escotismo, de no intuición intelectual respecto del singular material (que no equivale a no-conocimiento, pues se admite un conocimiento indirecto y reflexivo: per quandam reflexionem $)^{36}$.

En consecuencia, Kant entiende que no puede haber un conocimiento metafísico ilimitado, sin frontera alguna, sino que, si es posible, se ha de atener en todo caso a las limitaciones impuestas por nuestra intuición. Todo lo que no pueda apoyarse en una experiencia posible debe ser considerado como "idea pura", sin un uso "trascendente", fuera del sujeto pensante.

\footnotetext{
${ }^{35}$ Cf. Aristoteles: De anima II, 1, 412a19-21.

${ }^{36}$ Cf. nuestro estudio citado: "Abstracción e Intuición en Guillermo de Ockham...", pp. 250-253.
} 
Pero esto estaba ya previsto de alguna manera por Aristóteles, al hablar de la ciencia buscada, como "ciencia divina" o propia posesión sólo de los dioses, no posesión humana ${ }^{37}$.

$\mathrm{Y}$ en su comentario Tomás de Aquino corrobora esta visión ${ }^{38}$. Y por lo que hace a la parte metafísica, que se corresponde con la teología filosófica, la limitará a un conocimiento extrínseco y causal de Dios (respecto de la necesidad de su existencia a partir de lo contingente y finito). Pero señalando también la limitación estricta respecto de su esencia, de la cual, sólo tenemos un conocimiento negativo, ciencia negativa ${ }^{39}$. Esta teología filosófica es, por otra parte, totalmente diferente de la teología religiosa, que se apoya en la fe religiosa (lo que no estaba claro en la tradición platónico-agustiniana):

Así pues, la teología o ciencia divina es doble: una en la que lo divino es tratado, no como objeto propio (subiectum) de la ciencia, sino como fundamento del objeto propio [principia subiecti; fundamentos del ser] y tal es la teología filosófica, que por otro nombre se dice metafísica. La otra es aquella en la que lo divino es tratado por sí mismo como objeto propio de la ciencia; y tal es la teología que se deriva de la escritura sagrada. Ambas versan ciertamente sobre objetos separados de modo real (secundum esse) de la materia y del cambio físico; pero de modo diverso, según que un ser puede hallarse de doble manera separado realmente de la materia y del cambio físico: un modo es tal que es intrínsecamente inherente a la cosa que se dice separada realmente de la materia y del cambio físico, el no poder existir en la materia. El otro es tal que, [a la cosa separada] no le es inherente intrínsecamente el tener que existir en la materia y el

${ }^{37}$ Cf. ARISTÓteles: Metaphys. I, 2, 983a2-11.

${ }^{38}$ Cf. Tomás De AQuino: In Metaphys. Arist. I, lec. 3, nn. 60 y 64.

39 "De superioribus rebus in scientiis maxime tractatur per viam remotionis $[\ldots]$ Unde multo magis immateriales substantiae a nobis cognosci non possunt, ut earum quidditates apprehendamus; sed de eis nobis in scientiis documenta traduntur per viam remotionis, et alicuius habitudinis ad res materiales." $S$. Theol. I, 88, 2, 2m. Cf. S. Theol. I, 88,2 , ad $1 \mathrm{~m}$; a. 3 , etc. 
cambio físico, sino que puede existir sin materia y sin cambio; aun incluso cuando algunas veces se halle en la materia. Así el ente, la substancia, la potencia y el acto, etc. se hallan separados de la materia y del cambio físico, por que no dependen necesariamente (secundum esse) de la materia [...] Así pues, la teología filosófica trata de lo separado según este segundo modo como de sus objetos propios (subiecta) y de lo separado en el primer sentido como de los principios del objeto propio; mientras que la teología religiosa trata de lo separado según el primer sentido como de sus propios objetos $^{40}$.

Así, pues, dejando de lado ahora las posiciones, tanto de los que no ven limitación alguna en el conocimiento metafísico (conceptualismo, ontologismo, idealismo), como de los que no ven siquiera la posibilidad de un conocimiento superior a las impresiones sensibles (empirismo), vamos a centrarnos en los que, como Kant y Tomás de Aquino, entienden que la metafísica humana, en cualquier caso, no puede llevarse a cabo sin tener en cuenta importantes limitaciones.

\footnotetext{
${ }^{40}$ "Sic ergo, theologia sive scientia divina est duplex. Una in qua considerarantur res divinae non tamquam subiectum scientiae, sed tamquam principia subiecti, et talis est theologia, quam philosophi prosequuntur, quae alio nomine metaphysica dicitur. Alia vero, quae ipsas res divinas considerat propter seipsas ut subiectum scientiae, et haec est theologia quae in sacra scriptura traditur. Utraque autem est de his quae sunt separata a materia et motu secundum esse, sed diversimode, secundum quod dupliciter potest esse aliquid a materia et motu separatum secundum esse. Uno modo sic, quod de ratione ipsius rei, quae separata dicitur, sit quod nullo modo in materia et motu esse possit, sicut deus et angeli dicuntur a materia et motu separati. Alio modo sic, quod non sit de ratione eius quod sit in materia et motu, sed possit esse sine materia et motu, quamvis quandoque inveniatur in materia et motu. Et sic ens et substantia et potentia et actus sunt separata a materia et motu, quia secundum esse a materia et motu non dependent, sicut mathematica dependebant [...] Theologia ergo philosophica determinat de separatis secundo modo sicut de subiectis, de separatis autem primo modo sicut de principiis subiecti. Theologia vero sacrae scripturae tractat de separatis primo modo sicut de subiectis". TOMÁs DE AQuino: In Boeth de Trinit., q. 5, a. 4c; ed. B. Decker, Leiden: Brill 1955.
} 


\section{Las limitaciones del conocimiento metafísico (Kant y Tomás de Aquino)}

La reunión de ambos autores en torno a este tema no significa para nosotros que haya una perfecta coincidencia en cuanto a las razones para diseñar los límites del conocimiento metafísico. Sería desconocer las profundas diferencias en cuanto al enfoque mismo de la Metafísica, que existen entre el aristotelismo tomista y el idealismo trascendental kantiano.

La más radical ha quedado insinuada anteriormente: mientras que Kant no puede entender que la Metafísica pueda realizarse a partir de la experiencia, sino que toda ella y en todas sus partes ha de ser un saber puro a priori — tal y como lo recibe de la tradición racionalista— en cambio para un aristotélico como Tomás de Aquino - y siendo fiel al principio de que nada es conocido que no haya pasado por la experiencia- entiende que la Metafísica ha de partir de la experiencia misma del ser real y de sus condiciones de finitud, variabilidad, contingencia o efectividad, multiplicidad, gradación perfectiva, proyección hacia metas ulteriores, etc. Aunque el término o punto de llegada sea el del análisis mismo radical de lo que es ser y no-ser, y de sus categorías básicas reales, así como de las propiedades que de suyo (per se) le competen (propiedades trascendentales), etc. Por ello entendemos que la crítica kantiana de la Metafísica se ha de entender respecto de la metafísica racionalista y contra ella es eficaz; pero no afecta en absoluto al estilo de la metafísica de inspiración aristotélica.

La anterior diferencia es causa de otras, ya que Kant extiende las limitaciones hasta excluir de la razón especulativa todo conocimiento de los objetos clásicos de la metafísica —Dios, la libertad y la inmortalidad; ${ }^{41}$ mientras que en la metafísica de Tomás de Aquino se admite, al menos, el conocimiento existencial de tales "objetos", aunque se coincide tam-

\footnotetext{
${ }^{41}$ "Ni siquiera puedo, pues, aceptar a Dios, la libertad y la inmortalidad en apoyo del necesario uso práctico de mi razón, sin quitar, a la vez, a la razón especulativa su pretensión de conocimientos exagerados" (KrV., B XXX).
} 
bién en cuanto al agnosticismo del conocimiento esencial y positivo de los mismos, como luego veremos.

Dicho lo anterior, cabe que respecto del tema de los límites del conocimiento metafísico haya una básica y sugestiva coincidencia; y ello, como veremos, incluso en cuanto a algunas de las razones para señalar tales limitaciones.

Pero lo primero que vamos a estudiar es la causa o raíz de las extralimitaciones, que históricamente se han dado y pueden darse respecto del conocimiento metafísico, desde la perspectiva de ambos sistemas.

\subsection{Las aspiraciones naturales de la razón humana, como raíz de las extralimitaciones}

Señalemos de entrada, el perjuicio que producen las extralimitaciones, esto es, las concepciones excesivamente optimistas respecto del alcance de nuestro conocimiento metafísico. Tal perjuicio no es otro que el bascular de la razón, ante los fracasos experimentados, hacia el extremo contrario del escepticismo, que es como la autodestrucción o el suicidio de la propia razón. Dice Kant:

Me halaga el que, gracias a haber hecho este camino [de la crítica], haya encontrado el modo de acabar con todos los errores que hasta ahora habían dividido la razón consigo misma en su uso no empírico ( $K r V .$, A XII).

Y en otro texto:

El dogmatismo es, pues, el procedimiento dogmático de la razón pura sin previa crítica de su propia capacidad. Esta contraposición no quiere, pues, hablar a favor de la frivolidad charlatana bajo el nombre pretencioso de popularidad o incluso a favor del escepticismo, que despacha la metafísica en cuatro palabras. Al contrario, la crítica es la necesaria preparación previa para promover una metafísica rigurosa (KrV., B XXXVI). 
Kant ha señalado expresamente y magistralmente ese afán de conocimiento de la razón, como causa de los desvaríos y confusiones de la metafísica:

Ello explica el que, desde que la razón humana piensa, o mejor, reflexiona, no haya podido prescindir de la metafísica, pero tampoco presentarla suficientemente depurada de elementos extraños. La idea de esa ciencia es tan antigua como nuestra razón. ¿Y qué razón no especula, ya sea de forma escolástica, ya de forma popular? Debemos confesar, sin embargo, que la distinción de los dos elementos de nuestro conocimiento, de los que unos se hallan completamente a priori en nuestro poder, mientras otros únicamente pueden ser tomados a posteriori de la experiencia, quedó muy oscura incluso en pensadores de oficio. A ello se debe el que jamás se haya llegado a demarcar una clase de conocimientos - y, consiguientemente, la idea genuina- de una ciencia a la que durante tanto tiempo y tan intensamente se ha dedicado la razón humana (KrV., A 843/ B 871).

Un poco después de este texto señala Kant muy certeramente otra de las causas del oscurecimiento de la metafísica, cual es su "homogeneidad con las matemáticas"; se entiende desde el punto de vista de la metafísica racionalista:

Pero lo que también ha oscurecido la metafísica desde otro punto de vista ha sido el hecho de mostrar, como conocimiento a priori, cierta homogeneidad con las matemáticas, homogeneidad que, en lo que al origen a priori se refiere, emparenta ambas disciplinas, mientras que se pone de manifiesto una decisiva heterogeneidad en lo que atañe al modo de conocer por conceptos, propio de la metafísica, si se lo compara con el modo de juzgar a priori sólo por construcción de conceptos, propio de las matemáticas, en lo que atañe, consiguientemente, a la diferencia entre el co- 
nocimiento filosófico y el matemático. Esta decisiva heterogeneidad ha sido siempre notada, por así decirlo, pero nunca reducida a criterios claros (KrV., A 844/B 872).

A pesar de todo, Kant entiende que la Metafísica es "el coronamiento de la razón humana" y lo mismo que incita a la extralimitación, puede ser, si se mira críticamente, instrumento de corrección de errores:

Por ello mismo es también la metafísica lo que corona todo el desarrollo de la razón humana. Este coronamiento es indispensable, independientemente de la influencia que, como ciencia, tenga en relación con determinados fines, ya que considera la razón de acuerdo con aquellos elementos y aquellas máximas supremas que han de servir de fundamento incluso a la posibilidad de algunas ciencias y al uso de todas ellas. El hecho de que, como mera especulación sirva para evitar errores, más que para extender el conocimiento, no disminuye su valor, sino que, al contrario, le da dignidad y prestigio en virtud de la censura que ejerce, la cual asegura el orden universal, la armonía e incluso el bienestar de la comunidad científica ( $K r V$., A 851/B 879).

Si ahora nos volvemos a Tomás de Aquino en este punto, no es fácil encontrar una expresa censura general de las extralimitaciones posibles de la Metafísica, sino cuando se refiere al conocimiento, únicamente negativo, siempre insuficiente, respecto de ciertos objetos, como cuando afirma: "Las cosas de un orden superior no pueden ser conocidas de modo suficiente por las de orden inferior, ya que lo superior excede a lo inferior en cuanto a su modo y virtualidad" 42 .

\footnotetext{
${ }^{42}$ Tomas De AQuino: In librum de Causis, Lec. 7, n. 180. En el mismo lugar, dice que la causa primera es "simpliciter inenarrabilis"(n. 182). "Respecto de la primera Causa esto es lo máximo que podemos saber: que excede totalmente nuestra ciencia y nuestro lenguaje. Conoce a Dios de manera perfecta el que sostiene que cuanto de él podemos pensar o decir es siempre menos de lo que en sí es." In librum de Causis, lec. 6, n. 160; cf. In librum de Causis, n. 163, etc.; cf., entre otros, T. D. Humbrecht: "La théologie négative chez saint Thomas d'Aquin", Rev. Thomiste, 93 (1993), pp. 535-566; 94 (1994), pp. 71-99.
} 
Hay, con todo, una implícita advertencia, cuando, al hilo del texto aristotélico, insiste en que la Metafísica es una "ciencia propia de los dioses, no una posesión humana"; por lo que el hombre no puede utilizarla cuando quiera y como quiera ${ }^{43}$.

Por otro lado, en Tomás de Aquino hay una doctrina, más bien curiosa, que parece coincidir con la idea kantiana en cuanto a ser, no sólo una aspiración insaciable del espíritu humano, sino también quizás la causa de nuestras extralimitaciones; me refiero a su doctrina acerca del "deseo natural de ver a Dios". Se trata, pues, de una aspiración "natural", espontánea, de la mente racional como tal y al margen de cualquier connotación religiosa. Al parecer sería proporcional al deseo de conseguir el bien perfecto y la verdad perfecta, tal cual la experimenta cualquier hombre reflexivo y espiritual. Dice Tomás de Aquino:

Hay en el hombre como ingénito un deseo natural de conocer la causa, cuando intuye los efectos; de lo cual brota en los hombres la admiración. Por tanto, si el entendimiento de la criatura racional no pudiera llegar hasta la primera causa de las cosas, el deseo natural quedaría frustrado ${ }^{44}$.

Dejando de lado las múltiples interpretaciones y discusiones de los estudiosos sobre este tema, ${ }^{45}$ parece que esa propensión o deseo inextinguible a conocer la verdad total y la Causa primera del todo (omnium

${ }^{43}$ Cf. Tomás De Aquino: In Metaphys., I, lec. 3, n. 64-65. Ver el texto al final de este trabajo.

${ }^{44}$ Tomás DE Aquino: Sum. Theol. I, q. 12, a. 1, c. Sin embargo, tal elevación no es imposible, ya que nuestro entendimiento "secundum naturam a materia aliqualiter elevatus est, potest ultra suam naturam per gratiam ad aliquid altius elevari." Sum. Theol. I, q. 12, ad 3m. Aquí ven los teólogos la posibilidad de elevación de la creatura racional a un fin sobrenatural, en el que se cumplirían justamente las aspiraciones del intelecto humano a la verdad y al bien absolutos.

45 Entre otros cf. M. Cuervo: "El deseo natural de ver a Dios", Ciencia Tomista, 37 (1928), pp. 310-340; 38 (1928), pp. 332-348; 39 (1929), pp. 5-36. A. R. MotTE: "Pour le éxégse de I, q. 12, a.1", Notes et Communic. de BT., t. 1, pp. 125-130. J. E. O'MAhony: The desire of God in the Philosophy of St. Thomas, Dublin-Cork 1929. St. Vallaro: "De naturali desiderio videndi essentiam Dei", Angelicum, 11 (1934), pp. 133-170; "De natura capacitatis intellectus creati ad videndam divinam essentiam", Angelicum, 12 (1935), pp. 192-196; A. RAINERI: "De possibilitate videndi Deum per 
entium prima Causa) nos llevaría fácilmente a tomar por conocimiento científico lo que no es más que una creencia razonable.

En efecto, sería desproporcionado respecto de la virtualidad de nuestras facultades "naturales", como tales; y solamente proporcionado o adecuado, en el supuesto de una elevación gratuita del hombre a un plano superior, sobrenatural ${ }^{46}$. Ahora bien, esto último está ya fuera de la razón filosófica y atañe propiamente a la fe religiosa.

\subsection{La limitación desde el carácter propio de la intuición humana}

Una segunda limitación provendría del carácter propio de la intuición humana. Se da por supuesto que todo nuestro conocimiento intelectual ha de apoyarse y partir de un conocimiento inmediato y directo de lo real. A tal conocimiento suele denominarse "intuición".

Ahora bien, el platonismo en general y especialmente la llamada "escuela franciscana" han constituido un mito de la intuición, dándole un alcance que en realidad no posee ${ }^{47}$. Se presupone que nuestra intuición es similar a la divina, la cual de un golpe de vista abarca todo lo existente y lo no existente, lo actual y lo meramente posible. La diferencia estaría sólo en que, debido al dualismo antropológico estricto, habría que admitir en el hombre una doble intuición, incluso respecto del mismo objeto: la sensible y la intelectual. Así se defiende en esta corriente la intuición intelectual directa del singular material. En efecto, descartada la actividad abstractiva, no se ve otro modo de conocimiento intelectual de lo material que la intuición del mismo por el entendimiento. Hay aquí ya una incoherencia con el platonismo que está en la base de esta corriente: y es que Platón hubo de recurrir a las Ideas separadas, justamente por la

essentiam", Divus Thomas (Pl.), fasc. 4-6 (1936); y fasc. 1-2 (1937); J. I. JENQUINS: "Good and the object of natural inclination, in S. Thomas Aquinas", Med. Philos. theol., 3 (1993), pp. 62-96, etc.

${ }^{46}$ Cf. S. Theol. I, q.12, a. 4.

${ }^{47}$ Cf. nuestro estudio: "El problema acerca de la noción de intuición humana", Sapientia , 63 (2008), pp. 23-52. 
ininteligibilidad en acto de lo material y poder salvar la inteligibilidad de lo mismo.

Pues bien, si por intuición se entiende la acción inmediata y directa del objeto material presente sobre nuestras facultades cognoscitivas, tal como la entiende por ejemplo Escoto y también Kant, es imposible admitir intuición intelectual alguna.

Toda intuición posible, según Kant, es solamente la sensible o empírica: "El conocimiento o es intuición o concepto (Anschauung oder Begriff: Intuitus vel conceptus). La intuición se refiere inmediatamente (unmitelbar) al objeto y es singular" (KrV., B 377). "La intuición es el Analogon de una representación sensible del acto de ver" 48 .

La intuición es el modo por medio del cual el conocimiento se refiere inmediatamente a dichos objetos, y es aquello a que apunta todo pensamiento en cuanto medio. Tal intuición únicamente tiene lugar en la medida en que el objeto nos es dado. Pero éste sólo nos puede ser dado (al menos a nosotros los humanos) si afecta de alguna manera a nuestro psiquismo.

La capacidad (Rezeptivität) de recibir representaciones al ser afectados por los objetos, se llama sensibilidad (Sinnlichkeit). Los objetos nos vienen pues, dados, mediante la sensibilidad y ella es la única que suministra intuiciones (Anschauungen). Por medio del entendimiento los objetos son, en cambio, pensados (Gedacht) y de él proceden los conceptos (Begriffe). Pero todo pensar tiene que hacer referencia directa o indirectamente a intuiciones, y, por lo tanto, a la sensibilidad, ya que ningún objeto se nos puede dar de otra forma ( $K r V$., B 33).

Kant distingue, pues, una doble "intuición", la empírica y la pura. Pero esta segunda no es perceptora de objetos, sino que llama así a las formas puras a priori, tanto de la sensibilidad (espacio y tiempo) como

\footnotetext{
${ }^{48}$ Opus postumum, trad. de Felix Duque, Ed. Nacional 1983, XXII, 17, p. 490.
} 
del entendimiento (categorías) ${ }^{49}$. Propiamente hablando, la intuición que percibe objetos o en la que éstos nos son "dados" es únicamente la empírica $^{50}$.

En consecuencia, Kant niega reiteradamente la existencia de una "intuición intelectual", en el sentido propio de captación de objetos. En definitiva, dado que el intelecto versa sobre el mundo inteligible ${ }^{51}$ no recibe la impresión directa de lo sensible, no puede tener ninguna intuición acerca de ello. Ni consiguientemente sobre lo singular o concreto. Lo intelectual no puede ser afectado ni activado por lo sensible, ya que es de otro orden. Por ello, a partir de la experiencia no se puede extraer ni universalidad ni necesidad: éstas son formas puras a priori.

Ahora bien, si no hay en modo alguno una intuición intelectual, se sigue que nuestro entendimiento no puede ir más allá, en la captación de objetos reales, de lo que ofrece la intuición empírica. Y ésta se refiere evidentemente a lo material; nunca a objetos inmateriales.

En efecto, las formas puras a priori de la intuición intelectual pura no son más que conceptos puros del entendimiento, esto es, estructuras que nos sirven para "pensar" objetos y no tienen otra finalidad ni otro uso legítimo que el trascendental, nunca un uso trascendente; esto es, nunca son aplicables a objetos reales en sí mismos, sino a conceptos de objetos. Ello significa ni más ni menos que cualquier pretensión de sobrepasar los límites de la intuición empírica o de la experiencia posible, será una extralimitación de la razón, un ejercicio puramente "dialéctico" e ilusorio, si se pretende aplicarlo al conocimiento de algo real. Tal pretendida "onto-logía" no es más que logomaquia ${ }^{52}$. Y si se refiere a Dios o a los objetos de la metafísica, una "ontoteología".

\footnotetext{
49 "Esta forma pura de la sensibilidad puede ser llamada intuición pura [reine Anschauung] que reside a priori en el espíritu, incluso con independencia de un objeto real del sentido o de toda sensación, en calidad de simple forma de la sensibilidad" (KrV., B 35-36).

${ }^{50}$ Cf. $\mathrm{KrV}$., 67-68: "Si prescindimos de la sensibilidad, no podemos tener intuición alguna. Por ello mismo no es el entendimiento una facultad de intuición"; cf. también: KrV., A. 19.

${ }^{51}$ Cf. De mundi sensibilis..., \ 10.

${ }^{52}$ Cf. KrV. A 246-247, B 303-304.
} 
Ahora bien, la Metafísica en cuanto debe constar de este tipo de intuiciones o ideas puras a priori, según se vio, está limitada por ello mismo a ser una mera estructura regulativa de nuestros conceptos; pero al carecer de uso trascendente, no es aplicable al mundo real; o bien, tal aplicación no es más que una "ilusión" dialéctica.

Veamos ahora lo que dice Tomás de Aquino. Digamos de entrada que no encontramos en él una limitación tan drástica como en Kant. En efecto, Kant extiende los límites incluso respecto del mundo material: es posible una "Física", pero no una "Metafísica". Tomás de Aquino entiende que es posible también una "metafísica" en cuanto conocimiento inmaterial del ser, incluso del ser material; pero con estrictas limitaciones.

La razón se debe a que Tomás entiende que sí hay una intuición intelectual, no "pura", sino en dependencia de la experiencia y de la abstracción formal. Por este medio captamos la ratio entis ut sic, prescindiendo de qué tipo concreto de ente se trate. Ahora bien, esta ratio entis, no es necesariamente material ni inmaterial ${ }^{53}$. A esto se llama "juicio de inmaterialidad negativa". Esa captación de la forma o ratio entis en cualquier existente concreto, es una abstractio formae a subiecto o abstracción formal propiamente dicha. Como tal, es un conocimiento directo y no discursivo, no dianoético; pertenece a la nóesis, es una forma de intuición abstractiva o de "abstracción intuitiva", ya que no es discursiva ${ }^{54}$.

\footnotetext{
${ }^{53}$ Para Tomás de Aquino, cf. In Boeth. de Trinit q. V, a. 4, ad 5m. Cf. nuestros estudios sobre el tema: “'Il 'separato' come condizione e come oggetto della Metafisica”, en Divus Thomas 96 (1993), pp. 632-94; “Abstracción formal y Separación en la formación del ente metafísico", Sapientia 59 (2004), pp. 139-178.

${ }^{54}$ No podemos detenernos en explicar más la abstractio formae o abstracción formal y su sentido. Solamente diremos que se expresa justamente en los nombres abstractos puros, como por ejemplo "blancura", "humanidad", "entidad", "verdad", "unidad", "singularidad", "virtud", etc. Cada ciencia teórica ha de situarse y situar su punto de vista propio (objeto formal) a través de esta primera abstractio formalis: ella no es el objeto formal quod de la ciencia, sino el objeto formal quo o medio de inteligibilidad, tanto para las definiciones (principios inmediatos) como para las demostraciones de cada ciencia teórica o pura. Para mayor información debemos remitirnos a los trabajos citados sobre el tema.
} 
Pero tal intuición no se refiere ciertamente al singular material, sino a las formas puras abstractas, en las que la acción abstractiva (por medio del entendimiento agente) disuelve el singular concreto, y mediante ello capta la esencia o "forma esencial" como tal (per se) ${ }^{55}$.

Así pues, hay una diferencia notable con Kant, pero a la vez hay una coincidencia en cuanto a aceptar una limitación del conocimiento metafísico.

Por lo pronto, ambos coinciden, como es lógico, en admitir un desconocimiento o falta de intuición respecto de entidades puramente espirituales, al menos en cuanto a sus naturalezas o esencias.

Es, pues, claro que en modo alguno podemos conocer de modo primario y proprio (primo et per se) a las substancias inmateriales, que no caen bajo el sentido y la imaginación, y que es el modo propio de conocimiento para nosotros (nobis expertum) ${ }^{56}$.

Por lo que la Metafísica humana nunca puede llegar a un mundo positivamente espiritual. Tomás ha rechazado y criticado el camino que algunos filósofos árabes pretendieron por vía de sucesivas abstracciones de lo material: afirma que, si se abstrae de toda materia positivamente, entonces no es que conozcamos algo positivamente inmaterial, sino que

\footnotetext{
${ }^{55}$ Cf. S. Theol., I, 12, 4, 3m.: "intellectus noster potest in abstractione considerare id quod in concretione cognoscit. Etsi enim cognoscat res habentes formam in materia, tamen resolvit compositum in utrumque, et considerat ipsam formam per se.". Respecto a la coincidencia de las formas abstractas mediante abstracción formal y las formas puras kantianas hemos llamado la atención en otro estudio: cf. "¿Intuición pura o abstracción formal? (de Kant a Tomás de Aquino)", Pensamiento, 58 (2002), pp. 55-8.

56 “Sed secundum Aristotelis sententiam, quam magis experimur, intellectus noster, secundum statum praesentis vitae, naturalem respectum habet ad naturas rerum naturalium; unde nihil intelligit nisi convertendo se ad phantasmata, ut ex dictis patet. Et sic manifestum est quod substantias immateriales, quae sub sensu et imaginatione non cadunt, primo et per se, secundum modum cognitionis nobis expertum, intelligere non possumus." $S$. Theol., I, 88, 1c.
} 
no conocemos nada; sólo quedan puras palabras, vacías de contenido real $^{57}$.

Incluso coinciden en señalar la dificultad y consiguiente limitación en cuanto al autoconocimiento o conocimiento de la mente por sí misma.

Kant, por su parte, afirma:

Esta observación es de gran importancia, no sólo para confirmar nuestra anterior refutación del idealismo, sino, más todavía, para indicarnos las fronteras que limitan la posibilidad del autoconocimiento y la determinación de nuestra naturaleza, cuando se trata de extraerlo de la mera conciencia interna, sin la ayuda de la intuición empírica ${ }^{58}$.

Respecto de Tomás de Aquino, son bien conocidos los textos en que, frente a la corriente agustiniana, que pretende un conocimiento inmediato e intuitivo del alma por sí misma, él sostiene que sólo puede haber un conocimiento indirecto y discursivo, a través de sus propios actos, y ello incluso, casi sólo sirve para conocer su mera existencia, ya que conocer su naturaleza resulta sumamente difícil, incluso después de una diligente y sutil investigación ${ }^{59}$.

Respecto de lo material individual no hay tampoco intuición directa; solamente hay un conocimiento por vía indirecta o reflexiva (per quandam reflexionem $)^{60}$. Pero cabe un conocimiento intuitivo abstracto, en el sentido antes indicado de abstractio formalis. Ello hace posible una "metafísica", como saber de lo inteligible y de lo inmaterial; mas solamente

\footnotetext{
${ }^{57}$ Cf. S. Theol. I, 88, a. 2c. Cf. nuestro estudio: “Il 'separato' come condizione e come oggetto della Metafisica”, Divus Thomas 96 (1993), pp. 63-94.

58 "Diese ganze Bemerkung ist von großer Wichtigkeit, nicht allein um unsere vorhergehende Widerlegung des Idealismus zu bestätigen, sonder vilmehr noch, um, wenn vom Selbsterkenntnisse aus dem bloßen inneren Bewußtsein und der Bestimmung unserer Natur ohne Beihülfe äußerer empirischen Anschauungen die Rede sein Wird, uns die Schranken der Möglichkeit seiner solchen Erkenntnis anzuzeigen.” KrV., B 294, nuestra cursiva.

${ }^{59}$ Cf. S. Theol I, 87, 1c. Sobre la evolución del pensamiento tomista en esta materia cf. nuestro trabajo: "El autoconocimiento y la vía de acceso al conocimiento metafísico, según Tomás de Aquino”, Aquinas, 45 (2002), pp. 27-54, especialmente 43ss.

${ }^{60}$ Cf. S. Theol. I, q. 86, 1c.
} 
en un sentido negativo. De hecho, la misma definición de substancia, que sería el ens por excelencia, se define negativamente ${ }^{61}$.

En efecto, nuestro conocimiento acerca de naturalezas espirituales o puramente inteligibles es únicamente in umbra intelligentiae, en un plano de negatividad y de semejanza analógica, ${ }^{62}$ esto es, como negación de lo sensible y por mera semejanza proporcional. Con respecto de las naturalezas inteligibles puras nuestro intelecto se encuentra en situación similar, según la gráfica expresión aristotélica, como el ojo del búho a la luz del mediodía ${ }^{63}$.

\subsection{La limitación desde el objeto propio del entendimiento humano}

El final del punto anterior nos pone en la pista de otra coincidencia respecto a los límites de la metafísica humana. En el citado texto de Aristóteles se ofrece implícitamente una ley del conocimiento: la necesaria proporción entre el cognoscente y lo conocido, ya que deben constituir una misma cosa: intellectus in actu est intellectum in actu ${ }^{64}$. Por ello, la desproporción o desequilibrio entre sujeto y objeto tiene por resultado, o la ignorancia del objeto o una mayor dificultad y limitación en su conocimiento. Es un hecho de experiencia lo que sucede a nuestra vista respecto de objetos escasamente iluminados o excesivamente luminosos. La moderna psicología cognitiva hablará de "umbrales" máximos y mínimos, en relación con el conocimiento sensitivo. Pero ello es aplicable también al conocimiento intelectivo.

En el plano intelectivo, la ley de la proporción entendimiento-objeto inteligible, se traduce, en general, en este principio: "Lo más inteligible

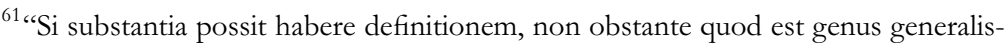
simum, erit eius definitio: substantia est res cuius quiditati debetur esse non in aliquo." De Pot. q. 7, a. 3, ad 4m. Cf. S. Theol. I, q. 3. a. 5, 1m; Quodlib. 9, 5, 2m, etc.

"62 "Ita ergo de formis inmaterialibus cognoscimus an est et habemus de eis loco cognitionis quid est cognitionem per negationem, per causalitatem et per excessum.” In Boeth, de Trinit. 6, a. 4. Cf. De Pot. q. 7, a. 5, ad 2m; etc.

${ }^{63}$ Cf. Metaph., I, 1, 993b9; Tomás DE AQuino: In Metaph. II, lec. 1, nn. 282-286.

${ }^{64}$ Cf. S. Theol. I, 24, 2c; 55, 1, 1m; C. Gentes., I, 44,4m; In Arist. De anima, III, lec. 9, n. 724 . 
en sí mismo no siempre es lo más inteligible para nosotros" o lo que mejor conocemos. De aquí la distinción clásica de un doble tipo de objeto inteligible: el adecuado o proporcionado y el posible o extensivo. Así, por ejemplo, en nuestra vista, el objeto proporcionado y propio es el color de las cosas materiales; pero el objeto secundario y extensivo es también su figura, su tamaño, movimiento, etc.

Referido esto a los objetos del entendimiento humano, el objeto extensible o "meramente posible de alguna manera", es todo lo que tiene razón de ser o lo verdadero en general; mientras que el objeto propio o proporcionado es la naturaleza o esencia de lo material (essentia vel quiditas rei materialis) ${ }^{65}$. En efecto, absolutamente hablando, podemos llegar a conocer "de alguna manera" cualquier ser o cualquier proposición verdadera; pero no podemos contemplar ni intuir más que las naturalezas de los entes materiales, y ello, como hemos indicado antes, por medio de una acción abstractiva de la forma esencial (forma totius) o esencia. En consecuencia, los objetos inmateriales o puramente inteligibles en sí caerían dentro del radio del objeto extensivo, pero desproporcionado, de nuestro intelecto; mas no dentro del radio mucho más limitado del objeto propio y proporcionado. En otras palabras, podríamos llegar a tener algún conocimiento negativo y analógico de los mismos, pero no un conocimiento propio y adecuado. La aplicación a la Metafísica es una mera consecuencia de estos principios.

En Kant no encontramos expressis verbis esta distinción de los objetos del entendimiento. Pero de alguna manera viene a coincidir con esto, tanto en la ley general de la proporción - y por ello hemos visto que niega decididamente, y en contra de toda la tradición racionalista, la intuición intelectual — cuanto en la necesidad, mil veces reiterada, de que nuestros conceptos se refieran a objetos de la experiencia posible.

Es verdad que esta referencia no tiene el mismo sentido o significado que en el aristotélico Tomás de Aquino. En Kant es una referencia por necesidad del uso, una referencia para que los conceptos tengan un

\footnotetext{
${ }^{65} \mathrm{Cf}$. "Quod intelligitur a nobis secundum statum praesentis vitae, est quidditas rei materialis, quae est nostri intellectus obiectum”. S. Theol., I, 88, 3c; cf. I, 84, a. 7; 85, a. $8 ; 87,2,2 \mathrm{~m}$.
} 
contenido o "materia" y no sean puras formas vacías. Mientras que en Tomás, la referencia es por razón del origen empírico de los mismos conceptos abstractos. Aquí se va desde lo empírico a lo abstracto o "forma inteligible"; en Kant la dirección va desde el concepto inteligible o forma pura a lo empírico, como "materia" sobre la que se ejercita o a la que subsume. Diríamos que en Kant hay un "realismo" descendente, deductivo; mientras que en Tomás de Aquino se trataría de un realismo "ascensional", a partir de la inducción empírica hacia los principios universales ${ }^{66}$.

Pero, aparte de esa diferencia interpretativa, en ambos casos se requiere la referencia a la experiencia y al mundo de lo sensible. Y ello implica admitir de una u otra forma que el objeto propio y adecuado de nuestra inteligencia no son las ideas puras y absolutas, lo incondicionado absoluto, sino lo real sensible. Y que solamente en cuanto usamos nuestros conceptos en el campo de la realidad sensible nuestro conocimiento intelectual posee una base realista. Esto, aplicado a la Metafísica, nos conduce lógicamente a una conciencia de ser un conocimiento limitado, y, en cierta forma, desproporcionado respecto de nuestra inteligencia humana en su estado actual ${ }^{67}$.

\footnotetext{
${ }^{66}$ Cf. Tomás de Aquino: In Analyt. Poster. II, lec. 20.

${ }^{67}$ Respecto de Kant, esta es la tesis de Heidegger: Kant und das Problem der Metaphysik (1929). Dice Heidegger: "Kant, sin embargo, quiere sustituir 'el orgulloso nombre de ontología' [ $K r V$., A 247, B 303] por el de 'filosofía trascendental', es decir, por el de una revelación de la esencia de la trascendencia. Y en esto tiene razón, si se toma el término 'ontología' en el sentido de la metafísica tradicional. Esta ontología tradicional 'pretende dar conocimientos sintéticos a priori de las cosas en general'. Va tan lejos que se convierte en un conocimiento óntico a priori, privilegio de un ser infinito." M. HeidegGer: Kant y el problema de la Metafísica, trad. de J. Ibscher Roth, México: FCE 1954, p. 110. Hay que reprocharle a Heidegger solamente que atribuya esa noción a la "ontología tradicional", sin distinción alguna; quizás porque él mismo ignora otros estilos de hacer ontología.
} 


\section{Epílogo tomista: Ens est id quod finite participat esse ${ }^{68}$}

Pudiéramos terminar con un epílogo tomista, a partir de la frase anterior; que significativamente se halla en un comentario a una obra de corte neoplatónico, el famoso libro De causis. En ningún otro texto de Tomás de Aquino se encuentra, que sepamos, una afirmación tan clara acerca de la finitud del ens, que es objeto de la Metafísica posible.

En efecto, frente a la posición de los que entienden el ens metafísico, como "abstrayendo de lo finito y de lo infinito"(Enrique de Gante [?], Escoto, Ockham, Fonseca, Suárez) Tomás señala que el ens ut ens es el ente finito, el que participa limitadamente (finite) del acto de ser (esse).

Tal metafísica, así limitada, es con todo suficiente para denominarse conocimiento "meta-físico", pues excede ciertamente el del mundo meramente físico, que implica la materia. Por otro lado, la ratio entis obtenida por medio de una abstractio formalis del acto de ser (esse, actus essendi) no implica necesariamente la materia, es negativamente inmaterial $^{69}$.

Una metafísica del ens, que "abstrae de lo finito e infinito", de lo actual y lo posible, e incluso de lo actual y del no-ser carece de sentido, ya que se trataría de un objeto absolutamente desprovisto de contenido, por efecto de la abstracción universalizante o "totalizante" (abstractio totalis, según Cayetano), que le ha despojado sucesivamente de toda diferencia y determinación. Es un ente vacío, como dirá luego Hegel con toda razón; es una mera palabra. Tal metafísica esencialista, es vacía e irreal. Como dirá Kant, no merece el pomposo nombre de "ontología"70 si ésta se entiende como conocimiento efectivo de un ser real.

Tal metafísica del ens finitum, en el plano de una inmaterialidad negativa, no puede ser más que un conocimiento igualmente negativo y li-

${ }^{68} \mathrm{El}$ texto completo dice: "Causa prima est supra ens, inquantum est ipsum esse infinitum. Ens autem dicitur id quod finite participat esse, et hoc est proportionatum intellectui nostro, cuius obiectum est quod quid est..."(In de Causis, lec. 6, n. 175).

${ }^{69}$ Cf. nuestros estudios: 'Il 'separato' come condizione e come oggetto della Metafisica", Divus Thomas 96 (1993), pp. 63-94 y pp. 85-89; "Abstracción formal y Separación en la formación del ente metafísico”, Sapientia 59 (2004), pp. 139-178.

${ }^{70}$ Cf. KrV., A 247; ver la acertada nota de Kant en B 302. 
mitado de formalidades reales, aunque no físicas. Es, con todo, suficiente para, desde esa inmaterialidad, estudiar mediante semejanzas analógicas y supuesto el principio de causalidad, la existencia de entidades totalmente inmateriales. Sólo que es consciente de que tal acceso es meramente negativo, al menos en cuanto a la determinación de sus atributos. Se constituye en una "metafísica negativa", ya que tales conceptos los conoce por mera negación de límites, no por intuición directa de lo infinito, eterno, simplicísimo, etc. Así, lo simplicísimo lo conocemos por mera negación de composición, no por intuición de algo verdaderamente simple; lo "eterno" por negación de duración sucesiva, el antes y el después, que definen el tiempo, etc.: lo necesario absolute, como lo que "no-puede-no-ser" (Aristóteles), etc.

Lo anterior está dicho desde el objeto de la metafísica. Pero desde el sujeto, que es el intelecto humano, el cual es una potencia de un forma unida a un cuerpo material, la limitación de su alcance es igualmente indudable.

Tal intelecto, por una parte, en cuanto depende de los materiales suministrados por la sensibilidad corpórea, no puede ir más allá, en cuanto a conocimiento propio y adecuado. En otras palabras, el objeto adecuado, proporcionado y formal de tal entendimiento es la naturaleza de lo material (essentia rei sensibilis) como dicen Tomás y sus seguidores ${ }^{71}$. Esto significa que no puede presumir de un conocimiento positivo y esencial de entidades de cuya esencia no tiene intuición directa. Es lo que sucede con las entidades metafísicas de la teología filosófica, acerca de las cuales conoce sólo lo que no son, mas no lo que $\operatorname{son}^{72}$. Y en ello se incluye también el conocimiento directo o intuitivo acerca de sí

\footnotetext{
71 "Per intellectum connaturale est nobis cognoscere naturas, quae quidem non habent esse nisi in materia individuali; non tamen secundum quod sunt in materia individuali, sed secundum quod abstrahuntur ab ea per considerationem intellectus". $S$. Theol., I, 12, 4. Cf. a. 11; q. 84, a. 7, 8; In de anima, III, lec. 8, etc. Cf. también Tomás de Vío Cayetano: In de ente et essentia, q. XV, n. 128ss. (Ed. Laurent, Taurini, Marietti 1934).

${ }^{72}$ La fórmula es también de Tomás de Aquino: "Quia de Deo scire non possumus quid sit, sed quid non sit, non possumus considerare de Deo quomodo sit, sed potius quomodo non sit”. S. Theol., I, q. 3, introd. Cf. Q. D. De anima, a. 16.
} 
mismo, que no puede ser intuición, sino un razonamiento a través de sus actos ${ }^{73}$. Es fácil conocer que tenemos alma, pero conocer qué sea el alma difficilimum est ${ }^{74}$.

Mas, por otra parte, este mismo intelecto es ratio, esto es, una facultad que posee la capacidad de saltar desde un conocimiento a otro, mediante conexiones lógicas o reales. Así, por ejemplo, mediante la conexión real que va desde el efecto a la causa (por medio del principio de causalidad), dado un efecto a posteriori, puede llegar a conocer la existencia de una causa proporcionada, o incluso cuando tal causa es muy superior al efecto. Por conexiones lógicas procede mediante razonamientos en los que utiliza las relaciones de condicional, de inclusión, de suma lógica, de negación, etc.

Esto último viene a significar que, aparte de un objeto proporcionado y adecuado a nuestro intelecto, cual es lo material sensible, habría un objeto extensivo, más amplio ciertamente, pero indirecto y conocido con limitaciones, tanto en lo causal como en la vía de la analogía, de negación, etc. En el razonamiento analógico se ha de tener en cuenta la disimilitud de los extremos, conectados por una semejanza meramente proporcional (analogía) no unívoca. En el razonamiento causal, si bien puede descubrirse algo sobre la naturaleza de la causa, pero si ésta es (y puede ser, sin contradicción) muy superior al efecto, el conocimiento de tal causa será muy limitado y analógico, si no ya simplemente negativo.

Sin embargo, en el radio de este objeto extensivo se encontraría el ser en toda su amplitud posible y la verdad en general. De aquí que, con las limitaciones indicadas, ello permitiría el acceso a algún tipo de conocimiento verdaderamente meta-físico. Este "objeto extensivo", con sus limitaciones, significa no obstante una "apertura" del entendimiento humano a toda verdad o a la verdad como tal, la verdad como conocida. Lo cual bien puede decirse "metafísica", siquiera como superior a los conocimientos o verdades meramente físicas o del mundo material. En efecto, el conocimiento por ejemplo del bien en general, de lo be-

\footnotetext{
${ }^{73}$ Para Sto. Tomás, frente a san Agustín, cf. nuestro estudio ya citado: "El autoconocimiento...", pp. 36-40.

${ }^{74}$ Cf. Q. D. Verit. q. 10, a. 8, ad $8 \mathrm{~m}$.
} 
llo, de lo justo, etc., dentro de sus limitaciones fácticas, es posible al ser personal humano. $\mathrm{Y}$ es claro que no se ciñe exclusivamente al mundo físico-material.

Concluimos, pues, con el comentario tomista al texto aristotélico:

La ciencia que es máximamente libre (libera) no puede ser una posesión de quien está sujeto de múltiples maneras a la servidumbre, como nuestra naturaleza humana, la cual en tantas cosas está sujeta a múltiples esclavitudes de la vida. Por lo que dicha ciencia no es una posesión humana. Nuestra naturaleza se halla, en efecto, sujeta a múltiples necesidades de la vida, que a veces nos distraen de lo que merece la pena ser buscado por sí mismo [...]

Es, pues, claro que se busca por sí misma una sabiduría tal, que no es posesión del hombre. Pues se entiende como "posesión" aquello de lo que uno puede usar libremente. Mas de la ciencia, que merece ser buscada por sí misma no puede el hombre usar libremente, ya se lo impiden frecuentemente las necesidades de la vida. Tampoco se halla al arbitrio del hombre, puesto que éste no puede acceder a ella de modo perfecto. Sin embargo eso poco que de ella puede llegar a conocer, es más importante que todo cuanto puede obtener por medio de las demás ciencias [...]

Efectivamente, la ciencia que trata acerca de Dios y de las causas primeras, o sólo Dios la posee, o, si no solo, al menos la posee en máximo grado. La posee él solo, en el sentido de una perfecta comprehensión; la posee de modo máximo, en cuanto que también en cierta manera es participada por el hombre, no ciertamente como una posesión, sino como algo prestado por Dios ${ }^{75}$.

Y un escolio sobre la "Ontoteología” en Tomás de Aquino.

\footnotetext{
${ }^{75}$ In Metaphys. Arist., I, lec. 3, nn. 60 y 64.
} 
Como hemos tratado en otra parte, ${ }^{76}$ Tomás de Aquino ha utilizado la ontología como instrumento para la reflexión sobre los datos de la fe. Esta puede llamarse "ontoteología", pero no en el sentido peyorativo en que suele usarse ese vocablo, después de Kant y sobre todo de Heidegger. Tal uso de la ontología por la teología cristiana ha sido desde antiguo (piénsese en las discusiones de los Concilios sobre la noción de "persona" para esclarecer los dogmas - en modo alguno para demostrarlosde la Trinidad y la Encarnación) un uso normal y justificado, pues pone la razón al servicio y como para beneficio de la creencia: lo cual es totalmente conforme a la naturaleza de nuestra mente, que es también el asiento propio de las creencias.

Ahora bien, hay otro sentido de "ontoteología", que sí es criticable: es el de la ontoteología derivada del ontologismo. Mas esta ontoteología no es la de Tomás de Aquino, sino que está justamente y abundantemente repudiada por él mismo.

Pensaba Kant certeramente que los males de la metafísica provenían de una falta de reconocimiento de límites. Efectivamente eso era lo que sucedía en la metafísica racionalista, que llega directamente a Kant a través de Ch. Wolff y A. Baumgarten; y que era la única metafísica que Kant conocía, heredera, no obstante de la metafísica platónico-agustiniana de la Edad Media, que llega al racionalismo cartesiano, muy probablemente, a través del filósofo español Francisco Suárez en sus famosas Disputationes metaphysicae. Era ésta una metafísica que versaba sobre el ente, en cuanto "abstrae de lo finito y de lo infinito"; 77 lo cual se refiere a la abstracción universalizante y supone ya una intuición previa de ambos, e implica lógicamente una capacidad ilimitada de conocimiento.

Esta metafísica es denominada "ontoteología", ya que parece enfocar la metafísica desde posiciones teologizantes; concebida a imitación del conocimiento divino que, al conocerse a sí mismo, desde sí mismo conoce todas las demás cosas; visualizando así todo el campo de la verdad; aunque con instrumentos supuestamente racionales, pero "sin

\footnotetext{
${ }^{76}$ Cf. "Tomás de Aquino y la Ontoteología", Ciencia Tomista 129 (2002), pp. 429-461.

${ }^{77}$ Cf. F. SuÁrez: Disput. Metaph. dis. 1, sec. 1, n. 26; dis. 2, sec. 2, nn. 15-20.
} 
apoyo de experiencia alguna y por medio de simples conceptos" ${ }^{\text {, }}$. Su trasfondo sistemático inmediato es el "ontologismo", según el cual "lo primero en el ser es también lo primero en el conocimiento: primum ontologicum est etiam primum logicum". Este tipo de metafísica desbordada en sus pretensiones, está llamada según Kant, a quedarse en una mera "analítica del entendimiento puro"( $\mathrm{KrV}$., A 247); esto es, analítica de puros conceptos, mas no de realidades.

Frente a este ontologismo, ya Tomás de Aquino había dicho: "no es necesario que todo lo que es primario en el ser, sea también lo primero en el conocimiento" ${ }^{\text {"79 }}$. Y con respecto al ser, objeto de la especulación metafísica, entiende que es el ser finito: quod finite participat esse ${ }^{80}$. Por otro lado, el único camino de acceso posible es el de la "separación negativa" o el de la inmaterialidad negativa, no el de la intuición directa de lo espiritual ${ }^{81}$.

Consiguientemente la metafísica de Tomás de Aquino está en los antípodas de una metafísica ontologista. Es una metafísica ascendente, que camina consciente de sus limitaciones, por las vías de la separación negativa y de la analogía, que implica siempre desemejanza y por ello un amplio margen de agnosticismo razonable. Es consciente de que acerca de lo espiritual conoce más bien lo que no es que lo que es. Por eso rechaza los argumentos apriorísticos en la demostración misma de la existencia de un Ser Necesario y Perfecto. Nuestro concepto de lo necesario es ya radicalmente negativo ("lo que no-puede-no-ser") e igualmente el de ser perfecto, como el ser al que nada le falta de cuanto debe tener. Desgra-

\footnotetext{
${ }^{78} \mathrm{KrV}$., A 632.

${ }^{79}$ "Non est necessarium quod omne quod est primum in esse sit etiam primum in cognitione". S. Theol., I, 85. 3, 4m. Por ello rechaza también que lo divino sea lo primero que es conocido por la mente humana: cf. S. Theol., I, 88, 3; In Boeth. De Trinit., q. 1, a. 3. Sobre la acusación de "ontoteología” a Tomás de Aquino, cf. nuestro estudio: "Tomás de Aquino y la Ontoteología”, pp. 429-461.

80 "Causa prima est supra ens, inquantum est ipsum esse infinitum. Ens autem dicitur id quod finite participat esse et hoc est proportionatum intellectui nostro". In De Causis, Lec. 6, n. 175.

${ }^{81}$ Cf. nuestro estudio: "Abstracción formal y Separación en la formación del ente metafísico”, Sapientia 59 (2004), pp. 139-178.
} 
ciadamente, no siempre se ha entendido así, incluso dentro de ámbitos que se consideran sistemáticamente afines al aristotelismo tomasiano.

Frente a una "teología trascendental" u "ontoteología", que no distingue claramente las fronteras entre lo filosófico y lo teológico, entre lo credencial y lo racional, Tomás ha distinguido netamente y desde muy temprano como investigador, dos formas de Teología, enteramente diferentes como saberes (in ratione scibilis): la teología filosófica (que es metafísica) y la teología religiosa (derivada y basada en la revelación divina), como vimos anteriormente ${ }^{82}$.

Todo esto significa que, frente a una solapada opinión, que todavía prevalece en ciertas exposiciones, en Tomás de Aquino no se da confusión alguna entre razón y fe, entre creencias religiosas y convicciones filosóficas. Antes, bien, es quizás el primer teólogo cristiano que propugna claramente la distinción y, consiguientemente, la autonomía de cada disciplina en su propio campo de investigación ${ }^{83}$.

Por lo demás, la coincidencia con Kant en criticar la metafísica ontologista, no le obliga, como a Kant —y más modernamente a Heidegger y $\operatorname{otros}^{84}$-, a declarar imposible "toda metafísica", pues no es lo mismo un conocimiento metafísico "limitado", proporcionado a nuestro intelecto finito, que una metafísica "imposible". Kant es consecuente al rechazar la metafísica "dogmática" o racionalista, la única que él conoce. Tomás de Aquino, siguiendo a Aristóteles, ha sabido encontrar otro camino para una Metafísica ascensional posible, aunque limitada en sus pretensiones; por tanto, no dogmática, no ontologista, no caída del cielo empíreo.

Esto mismo nos permite advertir que toda la crítica kantiana a los argumentos ontológicos resulta eficaz contra los mismos, suponiendo, como supone Kant, que se parte de meros conceptos positivos sobre "ser infinito", "ser necesario", "ser realísimo", etc., como hicieron Descartes

\footnotetext{
${ }^{82}$ In Boeth de Trinit. q. 5, a. 4c; ed. B. Decker; Leiden: Brill 1955.

${ }^{83}$ Cf. C. Gent. II, 4: "Quod aliter considerat de creaturis philosophus et theologus": "Incluso cuando el filósofo y el creyente estudian algo en común acerca de las creaturas, lo hacen a la luz de principios diferentes".

${ }^{84}$ Sobre ello, remitimos a una obra bastante clarividente: G. KALINOWSKI: L' impossible Métaphysique, París: Beauchesne 1981.
} 
y Leibniz. Mas si se entiende que tales conceptos, como, por ejemplo, el de "ser absolutamente necesario" no son positivos, sino negativos, ${ }^{85}$ ello significa que no pueden usarse argumentalmente como puntos de partida (argumentos ontológicos), pero sí como términos de llegada en los argumentos a posteriori; como hace Tomás de Aquino.

Y con todo, esos términos de llegada, al ser conceptos negativos, no nos dicen lo que el "Ser absolutamente necesario" o el "Ser infinito" es, sino más bien lo que no es ( $S$. Theol. I, q. 3. pról.). Accedemos, así a una "teología negativa". Y no otra cosa significa el uso de la analogía (conceptos y términos analógicos) que es el ambiente conceptual propio de esa teología negativa, como requiere Tomás de Aquino reiteradamente. Pues en efecto, en todo concepto analógico, al aplicarlo al término de llegada (analogado secundario) la cualidad significada por el término análogo se ha de entender como simpliciter diversa y secundum quid eadem, como sabe cualquier tomista. ¿Qué otra cosa significa ese simpli-

\footnotetext{
${ }^{85}$ Así llegamos a la idea de "ser absolutamente necesario" o absolutamente incondicionado, como dice Kant, de modo negativo; esto es, a base de negar los condicionamientos que advertimos empíricamente en el ser condicionado o contingente. "Necesario absoluto" es también para un aristotélico lo que "absolutamente no puede no ser"; esto es, una idea negativa. Mas dado que no tenemos intuición alguna de semejante ser en sí mismo, de ello no tenemos conocimiento positivo, pero sí negativo, a base de negar las condiciones. Por ello no podemos partir de tal concepto para demostrar la existencia de un ser necesario absoluto, como hacen los ontologistas. Pero sí podemos llegar a comprender la necesidad de que exista un ser absolutamente necesario o totalmente incondicionado, como término de un razonamiento a posteriori, esto es, a partir de lo condicionado y contingente. En efecto, no todo cuanto existe puede ser condicionado, pues en tal caso, nada existiría. Algo que el mismo Kant parece admitir (cf. $\mathrm{KrV}$., A 586: "la razón es capaz, mediante un concepto a priori, de conocer un ser como incondicionado"). Salvo que se trate aquí de un concepto a priori, pues es una necesidad lógica a posteriori, basada en la existencia real de lo condicionado. En el fondo Kant ha caído parcialmente en el mismo defecto de los ontologistas, al suponer que los conceptos de "necesario absoluto" o de "infinito" son positivos y no negativos. Aunque está a punto de advertirlo, pues habla de "ser incondicionadamente necesario" ( $\mathrm{KrV}$., A 588): es claro que lo necesario por remoción de toda condición (incondicionado absoluto) es una idea negativa. Pero no falsa, ni puramente a priori, sino justamente a posteriori.
} 
citer diversa, sino de modo no unívoco, no positivo, sino negativamente respecto del punto de partida? ${ }^{86}$

En resumen, la crítica kantiana, siendo eficaz contra la ontoteología o teología ontologista, resulta completamente desarmada contra una metafísica y una teología que asume sus límites conceptuales; pero entendiendo, a la vez, que el carácter negativo de los conceptos "trascendentales" (en sentido tomista), si no es válido como punto de partida, sí lo puede ser como término al que se llega a posteriori, mediante la resolución metafísica del ens como tal, en sus principios. Y que aun siendo un conocimiento limitado, "con todo, eso poco que por medio de la metafísica se obtiene resulta mucho más gratificante que cuanto podemos obtener por medio de las demás ciencias especulativas", como dice Tomás, comentando a Aristóteles ${ }^{87}$. Por ello, terminamos con el mismo Aristóteles, para quien: "si bien las demás ciencias pueden ser más necesarias [para la vida del hombre, que la Metafísica], sin embargo más digna que ella, ninguna" 88 .

\footnotetext{
${ }^{86}$ Soy consciente de que todo esto implica también la nulidad de la crítica kantiana a la teología a posteriori de Tomás de Aquino. Y soy también consciente de que ello requeriría un desarrollo mucho más extenso, en el que ahora no podemos entrar. Pero confío en que cualquier lector puede por sí mismo hacer tal desarrollo.

87 'Illud tamen modicum quod ex ea habetur, praeponderat omnibus quae per alias scientias cognoscuntur”. In Metaphys., I, lec. 3, n. 60.

${ }^{88}$ Metaphys., I, 2, 983a10-11.
} 